Article

\title{
Reinforcement of Polylactic Acid for Fused Deposition Modeling Process with Nano Particles Treated Bamboo Powder
}

\author{
Cuicui Wang ${ }^{1,2}{ }^{0}$, Lee Miller Smith ${ }^{3}$, Wenfu Zhang ${ }^{2,4}$, Mingpeng $\mathrm{Li}^{2}$, Ge Wang ${ }^{2}$, \\ Sheldon Q. Shi ${ }^{3}$, Haitao Cheng ${ }^{2, *}$ and Shuangbao Zhang ${ }^{1, *}$ \\ 1 Beijing Key Laboratory of Wood Science and Engineering, Beijing Forestry University, Beijing 100083, China \\ 2 International Centre for Bamboo and Rattan, Beijing 100102, China \\ 3 Department of Mechanical and Energy Engineering, University of North Texas, Denton, TX 76207-7102, USA \\ 4 Zhejiang Forestry Research Institute, Hangzhou 310023, China \\ * Correspondence: htcheng@icbr.ac.cn (H.C.); shuangbaozhang@163.com (S.Z.); \\ Tel.: +86-010-8478-9830 (H.C.); +86-136-8159-3543 (S.Z.)
}

Received: 9 May 2019; Accepted: 26 June 2019; Published: 4 July 2019

\begin{abstract}
The focus of this report was to understand the tensile properties and dynamic mechanical properties of bamboo powder (BP) reinforced polylactic acid (PLA) composite filaments which were treated with nano calcium carbonate $\left(\mathrm{CaCO}_{3}\right)$, cellulose nanofibers (CNF), and micro-crystalline cellulose (MCC) using impregnation modification technology. The storage modulus $\left(E^{\prime}\right)$ of nano $\mathrm{CaCO}_{3}$-BP/PLA, MCC-BP/PLA, and CNF-BP/PLA composite filaments increased compared with $\mathrm{BP} / \mathrm{PLA}$ composite filaments before the glass transition temperature $T_{\mathrm{g}}$. When the temperature was above $T_{\mathrm{g}}$, the reinforcement effect of nano $\mathrm{CaCO}_{3}, \mathrm{MCC}$, and CNF gradually became less apparent. The loss modulus $\left(E^{\prime \prime}\right)$ and loss factor $\left(\tan \delta_{\max }\right)$ of the nano $\mathrm{CaCO}_{3}-\mathrm{BP} / \mathrm{PLA}, \mathrm{MCC}-\mathrm{BP} / \mathrm{PLA}$, and CNF-BP/PLA composite filaments was higher than that of BP/PLA composite filaments produced by the "one-step" method. The tensile strength (TS) results showed a similar trend. Compared with the control samples, the TS of nano $\mathrm{CaCO}_{3}$-BP/PLA, MCC-BP/PLA, and CNF-BP/PLA composite filaments produced by the "one-step" method (and the "two-step" method) increased by $40.33 \%$ (and 10.10\%), $32.35 \%$ (and $-8.61 \%$ ), and $12.32 \%$ (and $-12.85 \%$ ), respectively. The TS of nano $\mathrm{CaCO}_{3}-\mathrm{BP} / \mathrm{PLA}$, MCC-BP/PLA, and CNF-BP/PLA composite filaments produced by the "one-step" method was slightly higher than those produced by the "two-step" method. The elongation at break (EAB) of $\mathrm{BP} / \mathrm{PLA}$ composite filaments was higher than that of BP/PLA samples treated with nano $\mathrm{CaCO}_{3}$, MCC, or CNF. The PLA and modified BP were readily accessible through a simple mixing process. The rheological investigation of such mixtures showed that nano $\mathrm{CaCO}_{3}, \mathrm{CNF}$, and $\mathrm{MCC}$ have different effects on the processability and rheological properties of composites.
\end{abstract}

Keywords: cellulose nanofibers (CNF); micro-crystalline cellulose (MCC); nano calcium carbonate $\left(\mathrm{CaCO}_{3}\right)$; impregnation modification (IM); bamboo powder (BP); fused deposition modeling (FDM)

\section{Introduction}

Natural fibers are renewable materials that are derived abundant sustainable resources (e.g., bamboo, cotton, flax, hemp, jute, kenaf, sisal, ramie, pineapple, coir, etc.), which can be isolated, treated, and functionalized for a multitude of applications, for instance, polymeric matrix composites [1], etc. In polymeric matrix composites, natural fibers as a reinforcing phase, provide positive environmental benefits with respect to ultimate disposability and raw material use [2]. And natural fiber has many advantages such as low density, low cost, low energy consumption, high specific strength, and modulus, as well as a relatively reactive surface [3]. Natural fiber reinforced polymer composites have seen 
wide use in many industries including automotive, aerospace, electronics, construction, and interior decoration $[4,5]$. However, natural fiber reinforced polymer composites are used only to a limited extent in industrial practice, because the inherent polar and hydrophilic nature of natural fiber and the nonpolar performance of thermoplastics polymer, which leads to difficulties in compounding the reinforcement and the matrix. Thus, the acceptable dispersion levels and the effective composite materials cannot be obtained.

Recent research has reported that the inorganic nanoparticle impregnation is an effective method to improve the compatibility between natural fibers and polymer matrices [6]. The mechanical properties of single bamboo fibers and its composites treated with nano $\mathrm{CaCO}_{3}$ impregnation modification saw increased properties compared to the untreated samples $[7,8]$, as well as that of kenaf fibers and their composites were increased by impregnation with $\mathrm{CaCO}_{3}$ particles [9], which has a high surface hardness (1.5-4.7 GPa) and modulus of elasticity (73.5-85.5 GPa) [10]. Currently, cellulose nanofibers are attracting particular interest in both academia and industry because of the abundant renewable nature of cellulose, and the outstanding mechanical properties of cellulose nanocrystals [3,11]. Nano-cellulose can be used for the reinforcement of polymer composites where they are able to enhance their thermal stability and mechanical properties due to nano-cellulose having a large surface area, high aspect ratio, high crystalline structure, high on-axis stiffness (Young's modulus of 100-143 GPa) and a unique tensile strength $(0.8-10 \mathrm{GPa})[3,12,13]$. It also has been reported that nano-cellulose has a remarkable reinforcing effect on the tensile properties of bio-polymer composites [14-16]. Another cellulose-derived product, micro-crystalline cellulose (MCC) is a white, tasteless, and odorless crystalline powder, which can be used as a suspension- stabilizer, thickener, a filler, or binder in tablets, and a flow characteristics modifier in various formulations $[17,18]$. In comparison to nano $\mathrm{CaCO}_{3}$, the natural nanofillers has several advantages, including biosustainability, biorenewability, low production cost, and possibly lower cytotoxic and (pro-) inflammatory effects when inhaled [19]. Interestingly, cellulose nanofibers (CNF) and MCC have not been explored as polymer reinforcement that uses the impregnation modification technology to treat reinforcement.

The focus of this report is on the nano-particles treated bamboo powder/polylactic acid composite filaments for 3D printing, a technology in which a part can be built layer by layer to the desired geometry from virtual models based on computer-aided design software, digital scanning systems, or medical imaging systems. Moreover, complex parts can be built easily in reasonable time frames [20-24]. Presently, a large number of additive processes including fused deposition modeling (FDM), stereolithography (SLA), selective laser sintering (SLS), selective laser melting (SLM), digital light processing (DLP), laminated object manufacturing (LOM), and so on, are available for 3D printing. Tekinalp et al. [23] investigated short fiber reinforced acrylonitrile-butadiene-styrene (ABS) composites as a feedstock for 3D-printing in terms of their processibility, microstructure, and mechanical performance. Gurr et al. [25] reported an optically transparent stereolithography resin (SLR) filled with up to $30 \% \mathrm{w} / \mathrm{w}$ silica nanoparticles and observed an increase of the Young's modulus of $25 \%$ at a nanofiller content of $17 \% \mathrm{w} / \mathrm{w}$ without significantly impacting the optical properties; a higher nanofiller increased the stiffness by another $7 \%$ but the transparency was significantly reduced.

Currently, various nano-reinforcements have been used in 3D printed materials, including nano-cellulose [26], $\mathrm{SiO}_{2}$ [25,27], and layered silicate [28]. This is because nano-particles have a porous structure and the pores mainly pertain to mesopores and micropores, which indicated that they have an improved specific surface [29]. However, most of them were stereolithography (SLA) 3D printed materials. Fused deposition modeling (FDM) 3D printed nano-composites have not been fully studied. In this study, PLA was used as the matrix because of high elastic modulus, relatively low $T_{\mathrm{g}}$, and the possibility in 3D-printing, moreover, using dispersed high modulus inorganic particles to fill the PLA matrix may act as an additional fixed phase [30]. The study aimed to manufacture nano-reinforced bamboo powder (BP)/polylactic acid (PLA) composite filaments with high performance successfully used in FDM process, which can provide a new approach to explore the materials for FDM; contrast the treating effect of nano $\mathrm{CaCO}_{3}, \mathrm{CNF}$, and $\mathrm{MCC}$ on performance of $\mathrm{BP} / \mathrm{PLA}$ composite filament using 
the impregnation modification technology. The mechanical properties and interfacial properties of the composite filaments were examined using the mechanical property tests, dynamic mechanical analysis, rheological tests, and environmental scanning electron microscope (ESEM) examination.

\section{Materials and Methods}

\subsection{Materials}

Nano calcium carbonate $\left(\mathrm{CaCO}_{3}, 15-40 \mathrm{~nm}\right.$ grain diameter, NCCa40) was supplied by Beijing Boyu Gaoke New Material Technology Co., Ltd., Beijing, China. Micro-crystalline cellulose (MCC, A17730), with a particle size of $(1 \%+60$ mesh $(250 \mu \mathrm{m})$ and $<30 \%+200$ mesh $(75 \mu \mathrm{m}))$ and a bulk density of $0.25-0.35 \mathrm{~g} / \mathrm{cc}$, whose degree of polymerization is less than 350 , supplied by Alfa Aesar (by Thermo Fisher Scientific, Shanghai, China). Cellulose nanofibers (CNF, $1.089 \mathrm{mmol} / \mathrm{g}$ carboxyl content), with a diameter of $10 \mathrm{~nm}$ and a length of $2 \mu \mathrm{m}$, was prepared through TEMPO-mediated oxidation from NBKP, which was bought from Tianjin Haojia Nano-crystalline Cellulose Co., Ltd., Tianjin, China. Bamboo powder (BP) was obtained from Zhejiang Tenglong Bamboo Group Co. Ltd., Quzhou, China, and the particle size distribution of BP was presented in Table 1. Polylactic acid (PLA, 4032D), with a density of $1.24 \mathrm{~g} / \mathrm{cm}^{3}$ and melt flow index (MFI) of 7 (g/10 min-@210 ${ }^{\circ} \mathrm{C} / 2.16 \mathrm{~kg}$ ), supplied by NatureWorks (Blair, NE, USA). Analytically pure ethylenediamine tetraacetic acid disodium salt (EDTA-2Na) was purchased from Beijing Huabo Stand Biological Analysis Technology Co., Ltd., Beijing, China.

Table 1. The particle size distribution of bamboo powder (BP).

\begin{tabular}{ccccc}
\hline Particle size & $\begin{array}{c}<\mathbf{7 4} \boldsymbol{\mu m} \\
\text { (>200 Mesh) }\end{array}$ & $\begin{array}{c}\mathbf{7 4} \mathbf{1 2 4} \boldsymbol{\mu m} \\
\mathbf{( 1 2 0 - 2 0 0 ~ M e s h )}\end{array}$ & $\begin{array}{c}\mathbf{1 2 4} \mathbf{1 7 8} \boldsymbol{\mu m} \\
\mathbf{( 8 0 ~ 1 2 0 ~ M e s h )}\end{array}$ & $\begin{array}{c}\mathbf{> 1 7 8} \boldsymbol{\mu m} \\
\text { (<80 Mesh) }\end{array}$ \\
\hline Proportion & $33.75 \%$ & $16.53 \%$ & $45.56 \%$ & $4.15 \%$ \\
\hline
\end{tabular}

\subsection{Preparation of Modified Bamboo Powder}

Four specimen groups of BP were prepared for the experiment. The first specimen group was unmodified BP which was used as a control group. The other three specimen groups of BP were subjected to the impregnation modification process and were treated by nano $\mathrm{CaCO}_{3}, \mathrm{MCC}$, or $\mathrm{CNF}$, respectively. At $25^{\circ} \mathrm{C}, 100 \mathrm{~g}$ of $\mathrm{BP}$ were dissolved in $2000 \mathrm{~mL}$ of deionized water for $30 \mathrm{~min}$ at $60 \mathrm{rpm}$, $1.7 \mathrm{~g}$ of EDTA-2Na, and $20 \mathrm{~g}$ of nano $\mathrm{CaCO}_{3}, \mathrm{MCC}$, or CNF were then added to the mixture, which was then mixed for an additional $25 \mathrm{~min}$. The suspensions were then rinsed on a 200-nylon mesh net with deionized water and then air dried. The modified bamboo powder (MBP), which includes nano $\mathrm{CaCO}_{3}-\mathrm{BP}, \mathrm{MCC}-\mathrm{BP}$, and CNF-BP were obtained and preserved in a constant temperature and climate box at $23{ }^{\circ} \mathrm{C}$ and $50 \%$ relative humidity (RH).

\subsection{Composite Filaments Processing: Preparation of PLA-Based Composite Filaments by the "One-Step" Method and "Two-Step" Method}

In order to remove all absorbed moisture and prevent void formation, the BPs (particle size $<74 \mu \mathrm{m}$ ), nano $\mathrm{CaCO}_{3}$-BPs, MCC-BPs, and CNF-BPs were dried at $103^{\circ} \mathrm{C}$ in an oven until the moisture content (MC) was less than $2 \mathrm{wt} \%$. The PLA was first dried in an oven at $80^{\circ} \mathrm{C}$ for $4 \mathrm{~h}$, then at $100^{\circ} \mathrm{C}$ for $4 \mathrm{~h}$, and lastly at $110^{\circ} \mathrm{C}$ for $20 \mathrm{~h}$ before processing. The composite filaments were prepared by the following steps:

First, using a high-speed mixer, $20 \mathrm{wt} \%$ of $\mathrm{BP}$ or $\mathrm{MBP}$ (e.g., nano $\mathrm{CaCO}_{3}-\mathrm{BP}$, MCC-BP, and CNF-BP) and $80 \mathrm{wt} \%$ of PLA were added and mixed fully.

Second, in this study, two methods were used to manufacture the composite filaments, that is, the "one-step" method and "two-step" method. (1) "One-step" method (Figure 1): the composite filament was manufactured by placing the mixture directly in an intermeshing counter-rotating conical twin-screw extruder (PolyLab QC, HAAKE, Karlsruhe, Germany); (2) “Two-step" method (Figure 2): 
the mixture was granulated using twin-screw extruder. The mixture underwent melt mixing in the twin-screw extruder and then was passed through the die of the extruder forming the composites. The composites were then pelletized in a pelletizer machine to produce the granules. The granules obtained from the pelletizer machine were then placed in the twin-screw extruder with a die diameter of $3 \mathrm{~mm}$; where they were subjected to melt mixing and then water cooling to produce the composite filaments. In addition, the process was carried out at a temperature difference range of $175{ }^{\circ} \mathrm{C}, 175^{\circ} \mathrm{C}$, $170{ }^{\circ} \mathrm{C}$ between the feeding zone to die zone.

At last, the composite filaments with diameters of $1.75 \pm 0.05 \mathrm{~mm}$ were obtained by using a laser diameter measuring (LDM) gauge (Mercury-Tech) and the wiredrawing-winding machine (WWM-001, independent research and development).

\section{Compounds $\Rightarrow$ Twin-screw extruder $\Rightarrow$ LDM $\Rightarrow$ WWM-001 $\Rightarrow 1.75 \pm 0.05 \mathrm{~mm}$ filament}

Figure 1. The composite filaments prepared by the "one-step" method.

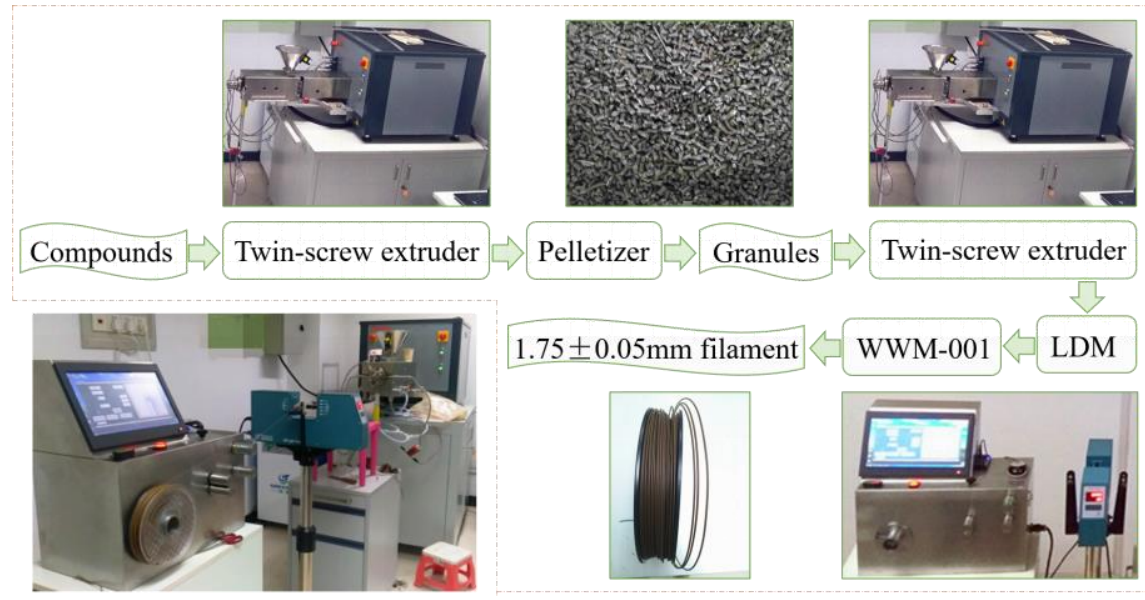

Figure 2. The composite filaments prepared by the "two-step" method.

\subsection{Rheological Studies}

The melt viscosity of the composites was studied using a HAAKE Polylab torque rheometer (HAAKE, Karlsruhe, Germany) equipped with a Rheomix 600 QC counter-rotating roller rotors mixing chamber. The mixing chamber was loaded at $70 \%$ volume capacity and all measurements were performed over a constant revolution speed $40 \mathrm{rpm}$ at a temperature of $170{ }^{\circ} \mathrm{C}$.

\subsection{Tensile Properties}

Tensile tests were carried out according to ASTM D 638-2010 using an Instron universal testing machine (Instron, Norwood, MA, USA). Tests were performed with a load cell of $500 \mathrm{~N}$ and a cross-head speed of $2 \mathrm{~mm} / \mathrm{min}$ on composite filament at room temperature $\left(25^{\circ} \mathrm{C}\right)$. The reported data were tensile strength (TS) and elongation at break (EAB). A minimum of five samples were tested for each formulation to get an average and standard deviation.

\subsection{Dynamic Mechanical Analysis (DMA)}

The storage modulus $\left(E^{\prime}\right)$, loss modulus $\left(E^{\prime \prime}\right)$, and loss factor $(\tan \delta)$ of composite filaments were carried out according to ASTM D $7028-07^{\varepsilon 1}$ using a dynamic mechanical analyzer (DMA Q800, TA Instruments, New Castle, PA, USA). DMA samples were vibrated with a tensile fixture at a frequency of $1 \mathrm{~Hz}$. The samples were subjected to an amplitude of $15 \mu \mathrm{m}$ in a temperature range of $-20^{\circ} \mathrm{C}$ to $120^{\circ} \mathrm{C}$ at a heating rate of $2{ }^{\circ} \mathrm{C} / \mathrm{min}$. 


\subsection{Morphology Observation}

The instrument used to analyze the surface morphology of the composite filaments and the interfacial quality between phases was a field emission environmental scanning electron microscope (ESEM; XL30 ESEM-FEG; FEI Co., Philips, The Netherlands). The samples were sputter coated with a thin layer of gold in a vacuum chamber for conductivity before the examination and were analyzed in a vacuum chamber that was less than $5 \times 10^{-5} \mathrm{~Pa}$ at a voltage of $7 \mathrm{kV}$.

\section{Results and Discussions}

\subsection{Rheological Properties}

Interfacial bonding between the reinforcement and matrix plays a vital role in determining the mechanical properties of the composites and the interfacial interactions of the composites can be reflected by rheology tests. Rheology investigates the flow of matter via recording the change in the parameters such as torque $(T)$, melt temperature $(T M)$, and total energy $(E)$ at a constant rotational speed. In general, the polymer melts exhibit non-Newtonian viscosity. Thus, aiming to investigate the effect of $\mathrm{CNF}, \mathrm{MCC}$, and nano $\mathrm{CaCO}_{3}$ on the rheological properties of composites in this study. Figure 3 showed a typical T-t, TM-t, and E-t plots of the blends test (e.g., BP and PLA, CNF-BP and PLA, MCC-BP and PLA, nano $\mathrm{CaCO}_{3}-\mathrm{BP}$ and PLA). There was a high initial $T$ value during the fusion of all the polymers followed by a sharp decrease during the $20 \mathrm{~min}$ test. The $T M$ of all the polymers rose sharply and then was followed by a general decrease, which is because the energy input reached a maximum value and the degradation of polymer reduced the viscosity during polymer melting and mixing process. As can be seen from Figure 3 that the balance torque $T_{\text {bal }}$ and the maximum melt temperature $T M_{\max }$ (the balance melt temperature $\left.T M_{\text {bal }}\right)$ were $0.2 \mathrm{Nm}$ and $177.10^{\circ} \mathrm{C}\left(176.2^{\circ} \mathrm{C}\right), 0.2 \mathrm{Nm}$ and $178.5^{\circ} \mathrm{C}\left(176.2^{\circ} \mathrm{C}\right), 0.1 \mathrm{Nm}$ and $176.2^{\circ} \mathrm{C}\left(176.2^{\circ} \mathrm{C}\right), 0.3 \mathrm{Nm}$ and $177.5^{\circ} \mathrm{C}\left(176.3^{\circ} \mathrm{C}\right)$ for BP/PLA, nano $\mathrm{CaCO}_{3}-\mathrm{BP} / \mathrm{PLA}, \mathrm{CNF}-\mathrm{BP} / \mathrm{PLA}$, and MCC-BP/PLA composite, respectively. It can be noted that the $T_{\text {bal }}, T M_{\max }$, and $T M_{\text {bal }}$ values of all the composites did not see a significant change. In addition, the $T_{\max }$ increased from $115.6 \mathrm{Nm}$ (CNF-BP/PLA) by $18.69 \%$ (to $137.2 \mathrm{Nm}$ ), $9.17 \%$ (to $126.2 \mathrm{Nm}$ ), $14.88 \%$ (to $132.8 \mathrm{Nm}$ ) while the maximum total energy $E_{\max }$ increased from $16.06 \mathrm{~kJ}$ (CNF-BP/PLA) by $44.33 \%$ (to $23.18 \mathrm{~kJ}$ ), $77.77 \%$ (to $28.55 \mathrm{~kJ}$ ), and $45.70 \%$ (to $23.4 \mathrm{~kJ}$ ) for BP/PLA, nano $\mathrm{CaCO}_{3}$-BP/PLA, and MCC-BP/PLA composite, respectively. BP treated by CNF impregnation modification was the easiest to mix with PLA, which is due to a lower $T_{\max }$ and $E_{\max }$. It can be inferred that the nano $\mathrm{CaCO}_{3}, \mathrm{CNF}$, and MCC each has a different impact on the rheological properties, suggesting that the incorporation of nano-particles into BP reinforced PLA composite filaments can result in disparate dispersion in the reinforcing phase due to the nanoscale dispersion and unique characteristics of the nano-particles. The good dispersion nano-particles can decrease the void numbers and provide strong interfacial hydrogen bond, thus developing better interfacial adhesion and improving the tensile properties of the composite filaments. It also can be inferred from these results that adopting nano $\mathrm{CaCO}_{3}$ to treat $\mathrm{BP}$ was better than using MCC and CNF to treat BP on the basis of the impregnation modification method. 


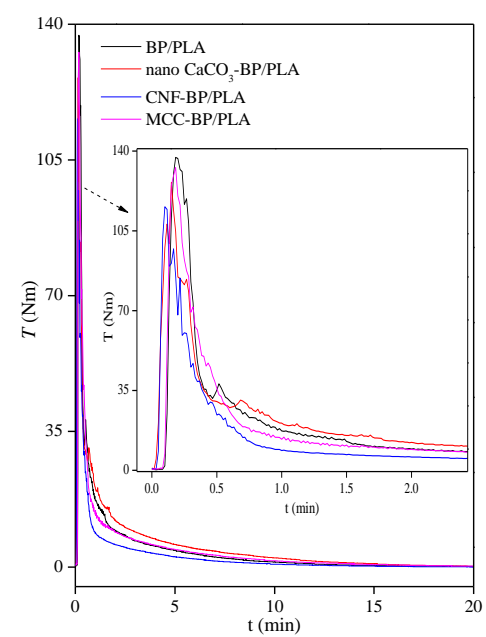

(a)

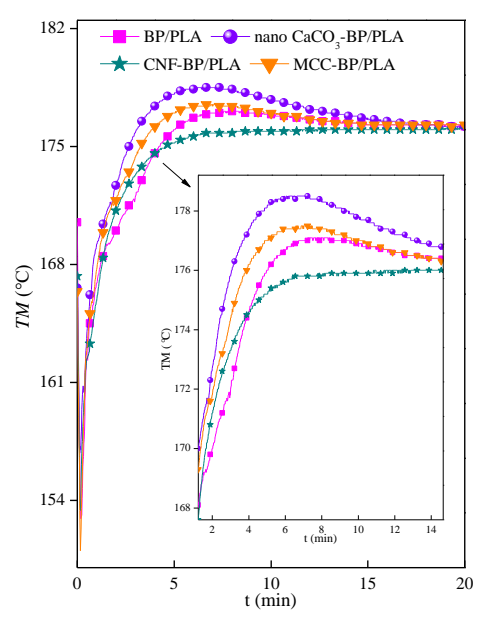

(b)

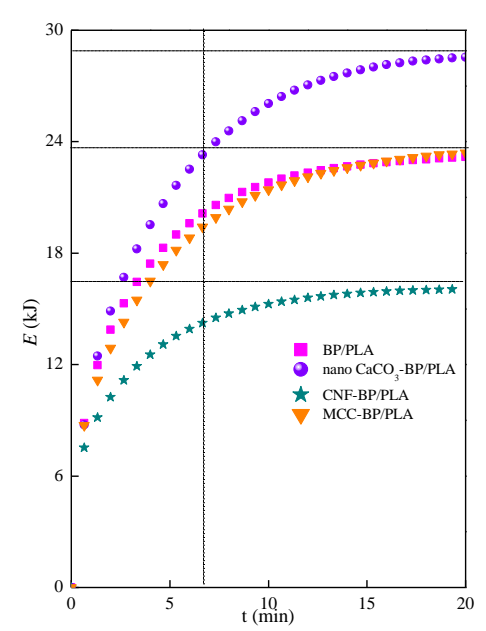

(c)

Figure 3. Torque $T$ (a), melt temperature $T M(\mathbf{b})$, and total energy $E(\mathbf{c})$ of nano-particles reinforced bamboo powder/reinforced polylactic acid (BP/PLA) composite filaments vary with the time.

\subsection{Tensile Properties of Composite Filaments}

The tensile strength (TS) results of BP/PLA, nano $\mathrm{CaCO}_{3}$-BP/PLA, MCC-BP/PLA, and CNF-BP/PLA composite filaments are shown in Figure 4 . When the composite filaments were prepared by "one-step" method, the TS of nano $\mathrm{CaCO}_{3}$-BP/PLA, MCC-BP/PLA, and CNF-BP/PLA composite filaments increased by $40.33 \%, 32.35 \%$, and $12.32 \%$, respectively, compared with BP/PLA composite filaments. The TS enhancement observed in these composite filaments can be explained by the formation of a percolating network in the polymer matrix, in which stress transfer is facilitated by hydrogen bonding. The hydrogen bonding was best exemplified in the paper where these secondary interactions provide the basis of its mechanical strength. Furthermore, well-dispersed nanometer-sized elements in the polymer matrix may also serve as nucleating agents in the foaming process [31]. Moreover, crystalline cellulose is much stronger and stiffer than the amorphous cellulose and cellulose itself, which means that MCC can be a better reinforcing agent than cellulose [32]. Khalia et al. [33] also reported that MCC with high crystallinity can deliver a strong reinforcing ability because of the high modulus, which is capable of improving the mechanical properties of biocomposites. However, when the composite filaments were manufactured by the "two-step" method, the TS of nano $\mathrm{CaCO}_{3}-\mathrm{BP} / \mathrm{PLA}$ increased by $10.10 \%$, while MCC-BP/PLA and CNF-BP/PLA composite filaments both decreased by $8.61 \%$ and $12.85 \%$, respectively. This is due to the fact that MCC and CNF existed in a net structure, which will reunite easily and sturdily because of the strong hydrogen bonding, which can affect the reinforcing effect. From Figure 4, it can be observed that except BP/PLA composite filaments, the TS result values of nano $\mathrm{CaCO}_{3}$-BP/PLA, MCC-BP/PLA, and CNF-BP/PLA composite filaments manufactured by the "one-step" method were slightly higher than those produced by "two-step" method. These higher TS values are due to the preparation process of the composite filaments, which causes PLA to degrade. The molecular chain of MCC and CNF contains a large number of hydroxyl groups, which can make PLA degrade enormously. It should be noted that CNF has more surface hydroxyl groups than MCC [34], which resulted in CNF-BP/PLA composite filaments having lower TS values than MCC-BP/PLA composite filaments. It also can be inferred that the effect of nano $\mathrm{CaCO}_{3}$ impregnation modification on TS of composite filaments was better than MCC and CNF impregnation modification. 


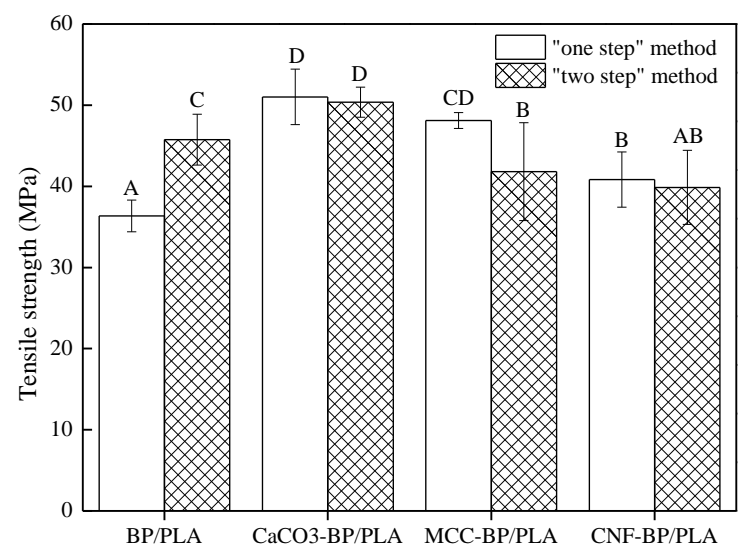

Figure 4. The tensile strength (TS) of reinforced polylactic acid (PLA)-based composite filaments. Note: There are significant differences at the 0.05 level of Duncan test and groups with the same letters do not differ statistically $(p<0.05)$.

Figure 5 illuminates the elongation at break (EAB) of BP/PLA, nano $\mathrm{CaCO}_{3}-\mathrm{BP} / \mathrm{PLA}$, MCC-BP/PLA, and CNF-BP/PLA composite filaments. Having used any of the fore-mentioned preparation methods, the $\mathrm{EAB}$ of $\mathrm{BP} / \mathrm{PLA}$ composite filaments was higher than that of $\mathrm{BP} / \mathrm{PLA}$ treated by nano $\mathrm{CaCO}_{3}$ or MCC or CNF. This is due to the formation of nano $\mathrm{CaCO}_{3}, \mathrm{MCC}$, and $\mathrm{CNF}$, which act as stress concentrators that lead to an increase of brittleness, which in turn reduces the EAB. Moreover, nano $\mathrm{CaCO}_{3}$ or MCC or CNF probabilistically come into contact with BP directly, leading to stress cracks that propagated much more easily through the material [35]. Compared to nano $\mathrm{CaCO}_{3}-\mathrm{BP} / \mathrm{PLA}$ composite filaments manufactured by the "one-step" method, the EAB of MCC-BP/PLA and CNF-BP/PLA composite filaments were increased by $10.04 \%$ and $6.99 \%$, respectively, this is because the melt plasticization process of MCC-BP/PLA and CNF-BP/PLA composite filaments during the "one-step" method process was better than that of nano $\mathrm{CaCO}_{3}-\mathrm{BP} / \mathrm{PLA}$ composite filaments. It also can be seen that the EAB of MCC-BP/PLA and CNF-BP/PLA composite filaments manufactured by the "two-step" method, decreased by $11.93 \%$ and $23.05 \%$, respectively, in comparison to nano $\mathrm{CaCO}_{3}$-BP/PLA composite filaments, indicating that MCC and CNF made the PLA in the composite filaments manufactured by the "two-step" degrade much more than in $\mathrm{CaCO}_{3}$.

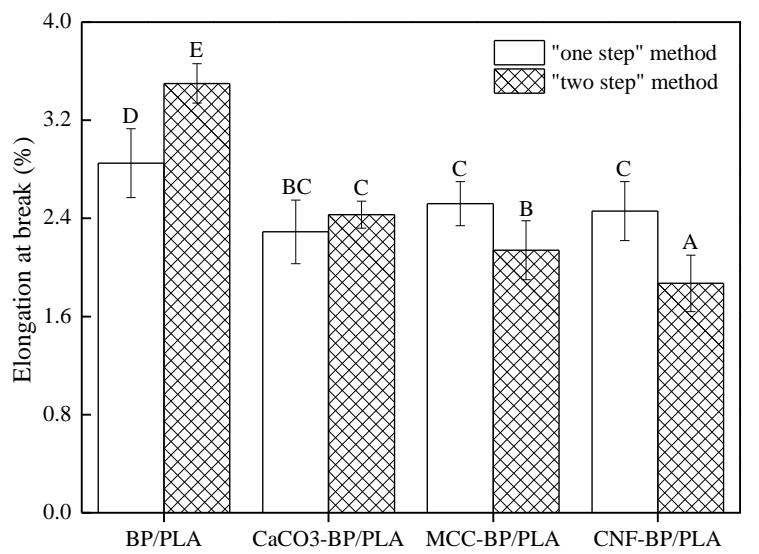

Figure 5. The elongation at break (EAB) of PLA-based composite filaments. Note: There are significant differences at the 0.05 level of Duncan test and groups with the same letters do not differ statistically $(p<0.05)$.

\subsection{Dynamic Mechanical Properties}

The storage modulus $E^{\prime}$, loss modulus $E^{\prime \prime}$ and loss factor $\tan \delta$ of the composite filaments as a function of temperature were determined by DMA and are shown in Figure 6. The DMA plots clearly 
revealed that the storage modulus $E^{\prime}$ of the nano $\mathrm{CaCO}_{3}$-BP/PLA, MCC-BP/PLA, and CNF-BP/PLA composite filaments increased compared with the BP/PLA composite filaments at the temperature ranging from $-20^{\circ} \mathrm{C}$ to the glass transition temperature $\left(T_{\mathrm{g}}\right)$. The reinforcement effect of nano $\mathrm{CaCO}_{3}$, MCC, and CNF gradually became less apparent when the temperature was above $T_{\mathrm{g}}$. This is because the rigid nanoparticles (e.g., nano $\mathrm{CaCO}_{3}, \mathrm{CNF}$, and MCC) further limited the movement of the matrix molecular segments, thus causing the improvement in rigidity of the composite filaments. The data showed a remarkable modulus enhancement in the glassy state, where at $-20^{\circ} \mathrm{C}, E^{\prime}$ increased from $3.345 \mathrm{GPa}$ (BP/PLA-0) by 56.17\% (to $5.224 \mathrm{GPa}$ ), 58.03\% (to $5.286 \mathrm{GPa}$ ), 38.48\% (to $4.632 \mathrm{GPa}$ ) for nano $\mathrm{CaCO}_{3}$-BP/PLA-0, MCC-BP/PLA-0, and CNF-BP/PLA-0 composite filaments, respectively; while $E^{\prime}$ increased from $4.322 \mathrm{GPa}$ (BP/PLA-1) by $16.06 \%$ (to $5.016 \mathrm{GPa}$ ) and $20.34 \%$ (to $5.201 \mathrm{GPa}$ ) for nano $\mathrm{CaCO}_{3}$-BP/PLA-1 and MCC-BP/PLA-1 composite filaments, respectively. It also can be seen that the $E^{\prime}{ }_{-20}^{\circ} \mathrm{C}$ of nano $\mathrm{CaCO}_{3}-\mathrm{BP} / \mathrm{PLA}-0$, and MCC-BP/PLA-0 composite filaments were a slight proportion higher than that of nano $\mathrm{CaCO}_{3}$-BP/PLA-1 and MCC-BP/PLA-1 composite filaments, respectively, which is consistent with the TS results. As can be seen from Figure $6 \mathrm{~b}$ that the $E^{\prime \prime}$ of the nano $\mathrm{CaCO}_{3}-\mathrm{BP} / \mathrm{PLA}, \mathrm{MCC}-\mathrm{BP} / \mathrm{PLA}$, and CNF-BP/PLA composite filaments were higher than that of BP/PLA-0, which means that the large friction occurred due to mutual movement. It can be inferred that the energy of the thermally activated molecular movement was different for all the composite filaments. The $\tan \delta_{\max }$ value of BP/PLA- 0 composite filaments were lower than nano $\mathrm{CaCO}_{3}-\mathrm{BP} / \mathrm{PLA}$, MCC-BP/PLA, and CNF-BP/PLA composite filaments (Figure 6c), which indicated that the $\mathrm{CaCO}_{3}$, MCC, and CNF had an effect on the movement of the PLA chain segments. Moreover, the crystallinity (CrI) of material can affect the dynamic mechanical properties, as it can be seen in the DMA curves [36], an increase in both storage and loss modulus in the temperature range of $90-120^{\circ} \mathrm{C}$ was observed, this is due to the re-crystallization exotherm of PLA, leading to the crystals formed during the cold crystallization of PLA around $95^{\circ} \mathrm{C}$ [37]. Additionally, it can be seen that the data of CNF-BP/PLA-1 (two-step method) composite filaments were not shown in Figure 6. This is because the EAB of CNF-BP/PLA-1 composite filaments was lower than the other materials, causing the higher brittleness, thus leading to the breakage which happened during the test. And according to the literature [38], the existence of CNF can improve the degradation rate from the beginning of degradation rather than in the process of degradation, which obviously improved the degradation of PLA.

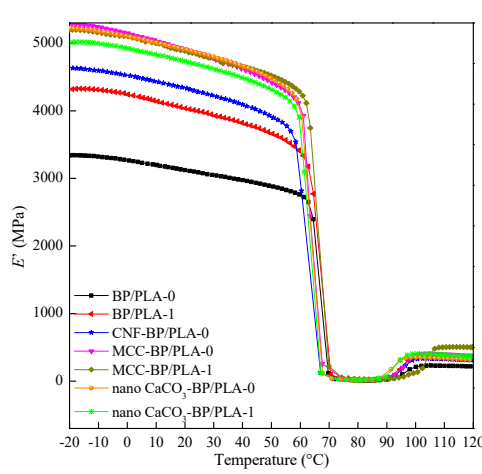

(a)

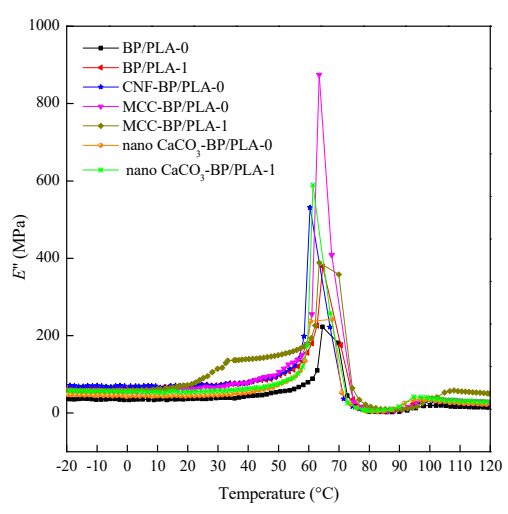

(b)

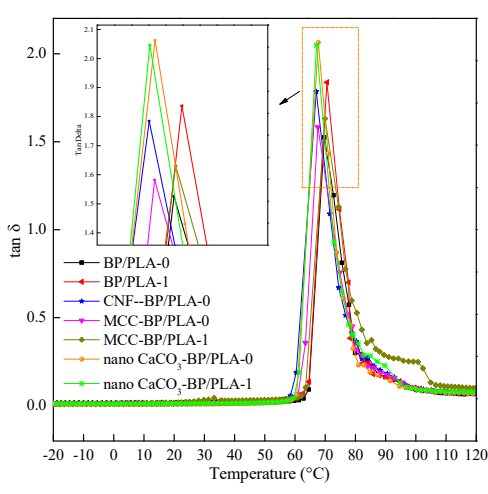

(c)

Figure 6. Storage modulus $E^{\prime}(\mathbf{a})$, loss modulus $E^{\prime \prime}(\mathbf{b})$ and loss factor $\tan \delta(\mathbf{c})$ of composite filaments. Notes: The BP/PLA-0, nano $\mathrm{CaCO}_{3}$-BP/PLA-0, micro-crystalline cellulose (MCC)-BP/PLA-0, cellulose nanofibers (CNF)-BP/PLA-0 composite filaments were manufactured by the "one-step" method (Figure 1); and BP/PLA-1, nano $\mathrm{CaCO}_{3}$-BP/PLA-1, MCC-BP/PLA-1, and CNF-BP/PLA-1 composite filaments were manufactured by the "two-step" method (Figure 2). 


\subsection{Morphology Observation}

Typical environmental scanning electron micrographs (ESEM) of the tensile fractured surfaces were presented in Figure 7. These figures were used to investigate the interface quality between nano-particles (e.g., nano $\mathrm{CaCO}_{3}, \mathrm{MCC}$, and CNF), BP, and PLA.

Figure 7 showed the corresponding ESEM images of BP/PLA, CNF-BP/PLA, MCC-BP/PLA, and nano $\mathrm{CaCO}_{3}$-BP/PLA composite filaments. Obviously, the level of interface adhesion between the reinforcement and matrix was reflected qualitatively by the ESEM micrographs. It can be seen that strong interface adhesion between modified $\mathrm{BP}$ (nano $\mathrm{CaCO}_{3}-\mathrm{BP}, \mathrm{MCC}-\mathrm{BP}$, and CNF-BP) and matrix PLA was obtained since less space or voids between both phases can be observed. During failure at the interface, the BP may not be able to support a load and could be easy to pull out from matrix PLA. It also can be noticed that the reinforcing phases broke under tensile tests except for the reinforcement pullout, which indicated that the load was transferred from the PLA matrix to the reinforcements effectively. It can be inferred that the development of interface bonding was a sign of the tensile properties' improvement in the composite filaments. The better interfacial interaction increased the tensile properties of the composite filaments manufactured by the "one-step" method, which was confirmed by the tensile testing results. In addition, according to the research $[39,40]$, the tensile properties were related not only to the interfacial compatibility but also to the raw materials themselves. For nano-particles reinforced composites manufactured by the "two-step" method, the effect of raw materials on tensile strength was more than the interfacial compatibility between reinforcement and matrix. It also can be observed that the "two-step" method made the matrix PLA of nano-particles reinforced composite filaments decrease much more than the "one-step" method, thus, decreasing the molecular weight of PLA. However, this phenomenon did not happen for the BP/PLA composite filaments.
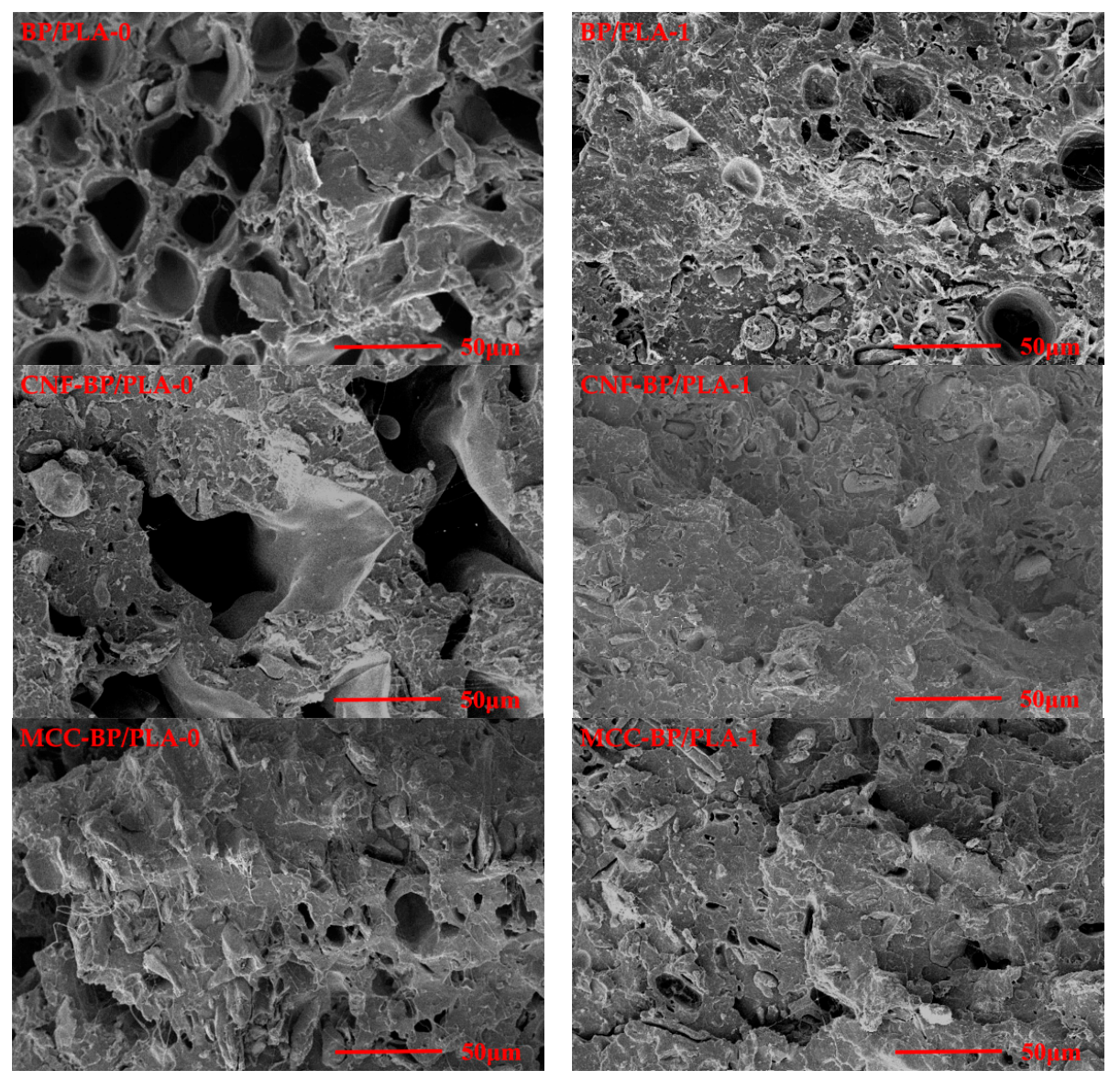

Figure 7. Cont. 

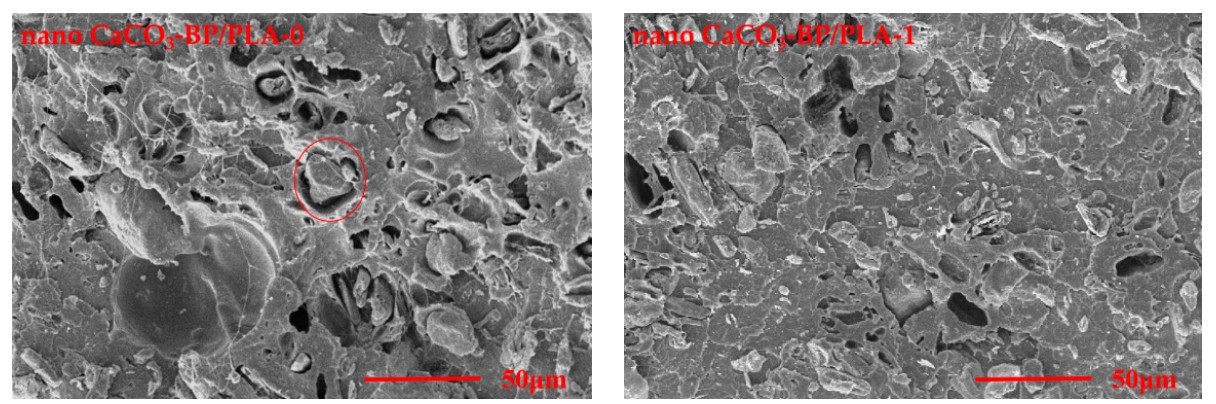

Figure 7. The tensile fracture surface of composite filaments. Notes: The BP/PLA-0, nano $\mathrm{CaCO}_{3}$-BP/PLA-0, MCC-BP/PLA-0, and CNF-BP/PLA-0 composite filaments were manufactured by the "one-step" method (Figure 1); and BP/PLA-1, nano $\mathrm{CaCO}_{3}-\mathrm{BP} / \mathrm{PLA}-1$, MCC-BP/PLA-1, and CNF-BP/PLA-1 composite filaments were manufactured by the "two-step" method (Figure 2).

\section{Conclusions}

Based on our main objective to produce natural fiber reinforced composite materials with strong interfacial adhesion for 3D printing, especially for fused deposition modeling, this work introduced nano-particles impregnation modification. In summary, the BP/PLA composite filaments were treated with nano $\mathrm{CaCO}_{3}, \mathrm{CNF}$ and MCC using impregnation modification and were successfully produced using both a "one-step" and "two-step" method. The TS of the composite filaments manufactured by the "one-step" method were remarkably improved by adding nano $\mathrm{CaCO}_{3}, \mathrm{CNF}$, and MCC. The TS of MCC-BP/PLA and CNF-BP/PLA composite filaments manufactured by the "two-step" method decreased due to the serious degradation of PLA. The TS of nano $\mathrm{CaCO}_{3}$-BP/PLA, MCC-BP/PLA, and CNF-BP/PLA composite filaments manufactured by the "one-step" method was slightly higher than those produced by the "two-step" method. The EAB of nano $\mathrm{CaCO}_{3}$-BP/PLA, MCC-BP/PLA, and CNF-BP/PLA was lower than that of the BP/PLA composite filaments, which is due to the increase in brittleness caused by impregnation modification. The $E^{\prime}$ of the composite filaments increased through the addition of nano $\mathrm{CaCO}_{3}, \mathrm{CNF}$, and $\mathrm{MCC}$ at the temperature ranging from $-20{ }^{\circ} \mathrm{C}$ to the $T_{\mathrm{g}}$, while the reinforcement effect of nano $\mathrm{CaCO}_{3}, \mathrm{MCC}$, and $\mathrm{CNF}$ gradually became less apparent when the temperature was above $T_{\mathrm{g}}$. The nano $\mathrm{CaCO}_{3}-\mathrm{BP}, \mathrm{MCC}-\mathrm{BP}$, or CNF-BP and PLA were readily accessible by the simple mixing process. A detailed rheological investigation of such mixtures showed that the nano $\mathrm{CaCO}_{3}, \mathrm{CNF}$, and MCC had a different impact on the processability and rheological properties of the composites. The effect of nano $\mathrm{CaCO}_{3}$ on the properties of composite filaments was better than MCC and CNF impregnation modification.

Author Contributions: C.W. and H.C. conceived and designed the experiments; W.Z., M.L., and C.W. performed the experiments; C.W. and W.Z. analyzed the data; H.C., S.Z., and G.W. provided materials/equipment/analysis tools; C.W. and W.Z. wrote the paper; L.M.S. and S.Q.S. modified the paper.

Funding: Beijing Forestry University first-class discipline construction project (2019XKJS0512); National Key R\&D Program of China (2017YFD0600802) and National Natural Science Foundation of China (31670571).

Acknowledgments: This study is financially supported by the Beijing Forestry University first-class discipline construction project (2019XKJS0512); the National Key R\&D Program of China (2017YFD0600802); the Co-Constructing Project of Beijing City Board of Education; the National Natural Science Foundation of China (31670571); the Beijing Natural Science Foundation (6162019); the Zhejiang Province Co-Constructing Project (CZXC201410) and the China Scholarship Council (CSC).

Conflicts of Interest: The authors declare no conflict of interest.

\section{References}

1. Pickering, K.L.; Efendy, M.G.A.; Le, T.M. A review of recent developments in natural fibre composites and their mechanical performance. Compos. Part A Appl. Sci. Manuf. 2016, 83, 98-112. [CrossRef] 
2. Eichhorn, S.J.; Baillie, C.A.; Zafeiropoulos, N.; Mwaikambo, L.Y.; Ansell, M.P.; Dufresne, A.; Entwistle, K.M.; Herrera-Franco, P.J.; Escamilla, G.C.; Groom, L.; et al. Review: Current international research into cellulosic fibres and composites. J. Mater. Sci. 2001, 36, 2107-2131. [CrossRef]

3. Azizi Samir, M.A.; Alloin, F.; Dufresne, A. Review of recent research into cellulosic whiskers, their properties and their application in nanocomposite field. Biomacromolecules 2005, 6, 612-626. [CrossRef] [PubMed]

4. Davoodi, M.M.; Sapuan, S.M.; Ahma, D.; Aidy, A.; Khalina, A.; Jonoobi, M. Effect of polybutylene terephthalate (PBT) on impact property improvement of hybrid kenaf/glass epoxy composite. Mater. Lett. 2012, 67, 5-7. [CrossRef]

5. Gupta, M.K.; Srivastava, R.K. Mechanical properties of hybrid fibers-reinforced polymer composite: A review. Polym. Plast. Technol. Eng. 2016, 55, 626-642. [CrossRef]

6. Shi, J.; Shi, S.Q.; Barnes, H.M.; Horstemeyer, M.F.; Wang, G. Kenaf bast fibers. Part II: Inorganic nanoparticle impregnation for polymer composites. Int. J. Polym. Sci. 2011, 7, 736474. [CrossRef]

7. Wang, C.C.; Xian, Y.; Cheng, H.T.; Li, W.Y.; Zhang, S.B. Tensile properties of bamboo fiber-reinforced polypropylene composites modified by impregnation with calcium carbonate nanoparticles. Bioresources 2015, 10, 6783-6796. [CrossRef]

8. Wang, C.C.; Song, W.; Cheng, H.T.; Yu, X.F.; Li, W.Y.; Zhang, S.B. Dipping modification with nano-CaCO 3 to improve tensile properties of individual bamboo fiber for developing bamboo-plastic composite. J. Nat. Fibers 2016, 13, 737-748.

9. Liang, K.; Shi, S.Q.; Wang, G. Effect of impregnated inorganic nanoparticles on the properties of the kenaf bast fibers. Fibers 2014, 2, 242-254. [CrossRef]

10. Presser, V.; Gerlach, K.; Vohrer, A.; Nickel, K.G.; Dreher, W.F. Determination of the elastic modulus of highly porous samples by nanoindentation: A case study on sea urchin spines. J. Mater. Sci. 2010, 45, 2408-2418. [CrossRef]

11. Svagan, A.J.; Samir, M.A.S.A.; Berglund, L.A. Biomimetic foams of high mechanical performance based on nanostructured cell walls reinforced by native cellulose nanofibrils. Adv. Mater. 2008, 20, 1263-1269. [CrossRef]

12. Tang, L.; Weder, C. Cellulose whisker/epoxy resin nanocomposites. ACS Appl. Mater. Interfaces 2010, 2, 1073-1080. [CrossRef]

13. Habibi, Y.; Lucia, L.A.; Rojas, O.J. Cellulose nanocrystals: Chemistry, selfassembly, and applications. Chem. Rev. 2010, 110, 3479-3500. [CrossRef]

14. El Achaby, M.; El Miri, N.; Aboulkas, A.; Zahouily, M.; Bilal, E.; Barakat, A.; Solhy, A. Processing and properties of eco-friendly bio-nanocomposite films filled with cellulose nanocrystals from sugarcane bagasse. Int. J. Biol. Macromol. 2017, 96, 340-352. [CrossRef]

15. El Miri, N.; Abdelouahdi, K.; Barakat, A.; Zahouily, M.; Fihri, A.; Solhy, A.; El Achaby, M. Bio-nanocomposite films reinforced with cellulose nanocrystals: Rheology of film-forming solutions, transparency, water vapor barrier and tensile properties of films. Carbohydr. Polym. 2015, 129, 156-167. [CrossRef]

16. Wang, L.F.; Shankar, S.; Rhim, J.W. Properties of Alginate-based films reinforced with cellulose fibers and cellulose nanowhiskers isolated from mulberry pulp. Food Hydrocoll. 2017, 63, 201-208. [CrossRef]

17. Adel, A.M.; Abd El-Wahab, Z.H.; Ibrahim, A.A.; Al-Shemy, M.T. Characterization of microcrystalline cellulose prepared from lignocellulosic materials. Part II: Physicochemical properties. Carbohydr. Polym. 2011, 83, 676-687. [CrossRef]

18. Wang, D.; Shang, S.B.; Song, Z.Q.; Lee, M.K. Evaluation of microcrystalline cellulose prepared from kenaf fibers. J. Ind. Eng. Chem. 2010, 16, 152-156. [CrossRef]

19. Clift, M.J.D.; Foster, E.J.; Vanhecke, D.; Studer, D.; Wick, P.; Gehr, P.; Rothen-Rutishauser, B.; Weder, C. Investigating the interaction of cellulose nanofibers derived from cotton with a sophisticated $3 \mathrm{D}$ human lung cell coculture. Biomacromolecules 2011, 12, 3666-3673. [CrossRef]

20. Sood, A.K.; Ohdar, R.K.; Mahapatra, S.S. Parametric appraisal of mechanical property of fused deposition modelling processed parts. Mater. Des. 2010, 31, 287-295. [CrossRef]

21. Zhong, W.; Li, F.; Zhang, Z.; Song, L.; Li, Z. Short fiber reinforced composites for fused deposition modeling. Mater. Sci. Eng. A 2001, 301, 125-130. [CrossRef]

22. Fu, S.Y.; Lauke, B.; Mader, E.; Yue, C.Y.; Hu, X. Tensile properties of short-glass-fiber and shortcarbon-fiber-reinforced polypropylene composites. Compos. Part A Appl. Sci. Manuf. 2000, 31, 1117-1125. [CrossRef] 
23. Tekinalp, H.L.; Kunc, V.; Velez-Garcia, G.M.; Duty, C.E.; Love, L.J.; Naskar, A.K.; Blue, C.A.; Ozcan, S. Highly oriented carbon fiber-polymer composites via additive manufacturing composites. Compos. Sci. Technol. 2014, 105, 144-150. [CrossRef]

24. Alaimo, G.; Marconi, S.; Costato, L.; Auricchio, F. Influence of meso-structure and chemical composition on FDM 3D-printed parts. Compos. Part B Eng. 2017, 113, 371-380. [CrossRef]

25. Gurr, M.; Hofmann, D.; Ehm, M.; Thomann, Y.; Kubler, R.; Mulhaupt, R. Acrylic nanocomposite resins for use in stereolithography and structural light modulation based rapid prototyping and rapid manufacturing technologies. Adv. Funct. Mater. 2008, 18, 2390-2397. [CrossRef]

26. Kumar, S.; Hofmann, M.; Steinmann, B.; Foster, E.J.; Weder, C. Reinforcement of stereolithographic resins for rapid prototyping with cellulose nanocrystals. ACS Appl. Mater. Interfaces 2012, 4, 5399-5407. [CrossRef]

27. Wozniak, M.; de Hazan, Y.; Graule, T.; Kata, D. Rheology of UV curable colloidal silica dispersions for rapid prototyping applications. J. Eur. Ceram. Soc. 2011, 31, 2221-2229. [CrossRef]

28. Gurr, M.; Thomann, Y.; Nedelcu, M.; Kubler, R.; Konczol, L.; Mulhaupt, R. Novel acrylic nanocomposites containing in-situ formed calcium phosphate/layered silicate hybrid nanoparticles for photochemical rapid prototyping, rapid tooling and rapid manufacturing processes. Polymer 2010, 51, 5058-5070. [CrossRef]

29. Niaza, K.V.; Senatov, F.S.; Kaloshkin, S.D.; Maksimkin, A.V.; Chukov, D.I. 3D-printed scaffolds based on PLA/HA nanocomposites for trabecular bone reconstruction. J. Phys. Conf. Ser. 2016, 741, 012068. [CrossRef]

30. Senatov, F.S.; Niaza, K.V.; Zadorozhnyy, M.Y.; Maksimkin, A.V.; Kaloshkin, S.D.; Estrin, Y.Z. Mechanical properties and shape memory effect of 3D-printed PLA-based porous scaffolds. J Mech. Behav. Biomed. Mater. 2016, 57, 139-148. [CrossRef]

31. Zeng, C.; Han, X.; Lee, L.J.; Koelling, K.W.; Tomasko, D.L. Polymer-clay nanocomposite foams prepared using carbon dioxide. Adv. Mater. 2003, 15, 1743-1747. [CrossRef]

32. Ashori, A.; Nourbakhsh, A. Performance properties of microcrystalline cellulose as a reinforcing agent in wood plastic composites. Compos. Part B Eng. 2010, 41, 578-581. [CrossRef]

33. Khalil, H.P.S.A.; Tye, Y.Y.; Leh, C.P.; Saurabh, C.K.; Ariffin, F.; Fizree, H.M.; Mohamed, A.; Suriani, A.B. Cellulose reinforced biodegradable polymer composite film for packaging applications. In Bionanocomposites for Packaging Applications; Springer International Publishing: Berlin, Germany, 2018; Chapter 3; pp. 49-69.

34. Ahmadi, M.; Madadlou, A.; Sabouri, A.A. Isolation of micro- and nano-crystalline cellulose particles and fabrication of crystalline particles-loaded whey protein cold-set gel. Food Chem. 2015, 174, 97-103. [CrossRef]

35. Wang, C.C.; Wang, G.; Cheng, H.T.; Zhang, S.B.; Smith, L.M.; Shi, S.Q. $\mathrm{CaCO}_{3}$ in situ treated bamboo pulp fiber reinforced composites obtained by vacuum-assisted resin infusion. Wood Sci. Technol. 2017, 51, 571-584. [CrossRef]

36. Tabi, T.; Sajo, I.E.; Szabo, F.; Luyt, A.S.; Kovacs, J.G. Crystalline structure of annealed polylactic acid and its relation to processing. eXPRESS Polym. Lett. 2010, 4, 659-668. [CrossRef]

37. Mofokeng, J.P.; Luyt, A.S.; Tabi, T.; Kovacs, J. Comparison of injection moulded, natural fibre-reinforced composites with PP and PLA as matrices. J. Thermoplast. Compos. Mater. 2011, 25, 927-948. [CrossRef]

38. Cui, X.X.; Qu, P.; Chen, P.; Zhang, L.P. Study on the degradation of cellulose nano whiskers/poly(1actic acid)composites. New Chem. Mater. 2010, 38, 107-139.

39. Song, W.; Zhang, K.Q.; Chen, Z.H.; Hong, G.H.; Lin, J.Y.; Hao, C.Y.; Zhang, S.B. Effect of xylanase-laccase synergistic pretreatment on physical-mechanical properties of environment-friendly self-bonded bamboo particleboards. J. Polym. Environ. 2018, 26, 4019-4033. [CrossRef]

40. Song, W.; Wei, W.B.; Li, X.F.; Zhang, S.B. Utilization of polypropylene film as an adhesive to prepare formaldehyde-free, weather-resistant plywood-like composites: Process optimization, performance evaluation, and interface modification. Bioresources 2017, 12, 228-254. [CrossRef]

(C) 2019 by the authors. Licensee MDPI, Basel, Switzerland. This article is an open access article distributed under the terms and conditions of the Creative Commons Attribution (CC BY) license (http://creativecommons.org/licenses/by/4.0/). 